\title{
miR-137 inhibits the proliferation of human non-small cell lung cancer cells by targeting SRC3
}

\author{
RUILIN CHEN, YONGQING ZHANG, CHENGCHENG ZHANG, HUA WU and SHUMEI YANG
}

Department of Respiratory Medicine, Shaanxi Provincial People's Hospital, Xi'an, Shaanxi 710068, P.R. China

Received September 16, 2015; Accepted January 17, 2017

DOI: $10.3892 / \mathrm{ol} .2017 .5904$

\begin{abstract}
Non-small cell lung cancer (NSCLC) is the most common type of lung cancer. The results of the present study demonstrate that high expression of microRNA (miR)-137 and low expression of steroid receptor coactivator-3 (SRC3) had a significant negative correlation in 40 NSCLC tissue samples. In addition, cell colony formation and proliferation was significantly reduced in miR-137-transfected A549 and NCI-H838 cells compared with scramble-transfected NSCLC cell lines. miR-137 was identified to induce $\mathrm{G}_{1} / \mathrm{S}$ cell cycle arrest and dysregulate the mRNA expression of cell cycle-associated proteins (proliferating cell nuclear antigen, cyclin E, cyclin A1, cyclin A2 and p21) in NSCLC cells. Notably, miR-137 could significantly suppress SRC3 3' untranslated region (UTR) luciferase-reporter activity, an effect that was not detectable when the putative 3'-UTR target-site was mutated, further clarifying the molecular mechanisms underlying the role of miR-137 in NSCLC. In conclusion, the results of the present study suggest that miR-137 suppresses NSCLC cell proliferation by partially targeting SRC3.
\end{abstract}

\section{Introduction}

Lung cancer is the leading cause of cancer-associated mortality, with high incidence rates worldwide (1). The majority of lung cancers are malignant carcinomas, and non-small cell lung cancer (NSCLC) accounts for $>80 \%$ of these (2). Although advances in treatment have occurred in the past few years, the survival rate for patients with NSCLC remains at $\sim 15 \%$ due to cancer metastasis and high recurrence rates (3). Therefore, it is necessary to further investigate the molecular mechanisms underlying the initiation of NSCLC development.

Changes to the expression of microRNAs (miRNAs/miRs) in tumors are a focus being studied at present and it has been

Correspondence to: Dr Shumei Yang, Department of Respiratory Medicine, Shaanxi Provincial People's Hospital, 256 West Youyi Road, Xi'an, Shaanxi 710068, P.R. China

E-mail: yshumei18@sina.com

Key words: miR-137, non-small cell lung cancer cells, steroid receptor coactivator-3, cell proliferation demonstrated that the dysregulation of miRNAs is involved in the malignancy of lung cancer $(4,5)$. miRNAs are endogenous non-coding 19-23 nucleotide long RNA molecules that are located on chromosome $1 \mathrm{p} 22$. It has been revealed that miRNAs can downregulate gene expression by binding to the $3^{\prime}$ untranslated regions (3'UTRs) of mRNA (6), thus affecting the proliferation, and metastasis of numerous types of cancer, such as gastric (7), breast (8) and lung cancer $(9,10)$. The expression of miR-137 has been identified to be significantly downregulated in lung cancer compared with healthy lung tissue (11). Similar results have been identified in glioblastoma (12) and colorectal cancer (13). Notably, the downregulation of miR-137 in lung cancer cells may be rescued following treatment with a DNA methylation inhibitor. Furthermore, miR-137 has a tumor suppressor function by directly targeting cell division cycle 42 (CDC42) mRNA to inhibit the proliferation and invasion of colorectal cancer cells (10). miR-137 has been revealed to be upregulated following preoperative capecitabine chemoradiotherapy in rectal cancer. In addition, a previous study reported that higher levels of miR-137 were associated with a poor response to therapy (14).

There has been a focus on identifying various tumor suppressor genes and oncogenes regulated by miRNAs in lung cancer, which can effect cancer cell survival and proliferation, such as solute carrier family 22 member 18 (SLC22A18) (15), KIT proto-oncogene receptor tyrosine kinase (16), kruppel like factor 8 (17), epidermal growth factor receptor and MET proto-oncogene receptor tyrosine kinase (18). Novel oncogenes and tumor suppressor genes are continuously being identified. Steroid receptor coactivator-3 (SRC3, also called NCOA3) (19) is a member of the SRC p1600 family that includes SRC1 (also called NCOA1 or F-SRC-1) and SRC2 (also called TIF2, GRIP1 or NCOA2) (20), which have been reported to be important oncogenes that are overexpressed in lung cancer, in which they promote tumor development and progression. In addition, SRC3 levels have been demonstrated to be elevated in breast cancer cells (21), a glucocorticoid-sensitive SCLC model (22), pancreatic adenocarcinoma (23), NSCLC cell lines (24) and NSCLC cells in vivo (25). Substantial data has demonstrated that overexpression of SRC3 may promote carcinoma cell proliferation, which is regulated by various miRNAs, such as miR-17-5, -17-92 and -195 (19,26).

Although a number of studies investigating the effects of miR-137 in lung cancer have been performed, the role of miR-137 in cell proliferation remains unclear. Whether the 
regulation of miR-137 is associated with the overexpression of SRC3 in lung cancer remains to be further investigated, which may aid in the development of novel strategies for the early diagnosis and treatment of lung cancer.

\section{Materials and methods}

Human tissue samples. NSCLC tissue and healthy tissue samples were collected between September 2014 and March 2015 during routine therapeutic surgery at the Department of Respiratory Medicine of Shaanxi Provincial People's Hospital (Xi'an, China). Written informed consent was obtained from all patients and the present study was approved by the Shaanxi Provincial People's Hospital Institutional Review Board.

Cell culture and transfection. Human NSCLC cell lines A549 and NCI-H838 (American Type Culture Collection, Manassas, VA, USA) were stored in the lab of Shaanxi Provincial People's Hospital. The A549 and NCI-H838 cells were cultured in Dulbecco's modified Eagle medium (DMEM) supplemented with $10 \%$ fetal bovine serum (FBS) (both Gibco; Thermo Fisher Scientific, Inc., Waltham, MA, USA), streptomycin $(100 \mu \mathrm{g} / \mathrm{ml})$ and penicillin $(100 \mathrm{U} / \mathrm{ml})$. A549 and NCI-H838 cells were incubated in a humidified atmosphere containing $5 \% \mathrm{CO}_{2}$ at $37^{\circ} \mathrm{C}$. miR-137 mimic (5'-UAUUGCUUGAGAAUA CACGUAG-3') and scramble control mimic (5'-UUCUCC GAACGUGUCACGUTT-3') were purchased from Guangzhou RiboBio Co., Ltd. (Guangzhou, China). Oligonucleotides were transfected into A549 and NCI-H838 cells when $80 \%$ confluency was achieved at a final concentration of $50 \mathrm{nM}$ using Lipofectamine ${ }^{\circledR} 2000$ (Invitrogen; Thermo Fisher Scientific, Inc.) according to the manufacturer's protocol.

Reverse transcription semi-quantitative polymerase chain reaction $(P C R)$. Total RNA was extracted from healthy lung and NSCLC tissue samples using TRIzol ${ }^{\circledR}$ reagent (Invitrogen; Thermo Fisher Scientific, Inc.). Total RNA (1 $\mu \mathrm{g})$ was reverse-transcribed into cDNA using ReverTra Ace transcriptase with random primers (100 ng) (both from Toyobo Co. Ltd., Osaka, Japan). Reverse transcription thermal cycling conditions were $10 \mathrm{~min}$ at $25^{\circ} \mathrm{C}$, followed by $40 \mathrm{~min}$ at $37^{\circ} \mathrm{C}$ and $10 \mathrm{~min}$ at $70^{\circ} \mathrm{C}$. Semi-quantitative PCR were performed using the StepOne ${ }^{\mathrm{TM}}$ Real-time PCR system (Thermo Fisher Scientific, Inc.) with the SYBR Green master mix (Applied Biosystems; Thermo Fisher Scientific, Inc.). Each PCR contained 100 ng cDNA and thermal cycling conditions were $2 \mathrm{~min}$ at $50^{\circ} \mathrm{C}$, followed by $10 \mathrm{~min}$ at $95^{\circ} \mathrm{C}$ and forty cycles of $10 \mathrm{sec}$ at $95^{\circ} \mathrm{C}$ and $1 \mathrm{~min}$ at $60^{\circ} \mathrm{C}$. The relative expression of miR-137, SRC3, proliferating cell nuclear antigen (PCNA), cyclin E, cyclin A1, cyclin A2 and p21 genes were validated using semi-quantitative PCR analysis. The primers used were as follows: miR-137 forward, 5'-GCGCTTATTGCT TAAGAATAC-3' and reverse, 5'-CAGTGCAGGGTCCGA GGT-3'; SRC3 forward, 5'-CGTCCTCCATATAACCGAGC-3' and reverse, 5'-TCATAGGTTCCATTCTGCCG-3'; PCNA forward, 5'-CCGGGACCTTAGCCATATTG-3' and reverse, 5'-GCTGAACTGGCTCATTCATCTC-3'; cyclin E1 forward, 5-'GCATCACAACAGAATATCATAA-3' and reverse, 5'-AAG CACCATCAGTAACATAA-3'; cyclin A1 forward, GACCTG TCACTGTCTTGTAC and reverse, CGTTTGGAGTGGTAG
AAATC; cyclin A2 forward, 5'-CACGTACCTTAGGGA AATGG-3' and reverse, 5'-CCAAATGCAGGGTCTCAT TC-3'; p21 forward, 5'-AAGACCATGTGGACCTGTCA-3' and reverse, 5'-CGTTTGGAGTGGTAGAAATCTG-3'. The expression level of $\beta$-actin was used as an internal control with the following primers: Forward, 5'-GTGGACATCCGCAAA GAC-3' and reverse, 5'-AAAGGGTGTAACGCAACTA-3'.

Soft agar colony formation assay. Colony formation assays in soft agar were performed to assess the proliferation ability of NSCLC cells following transfection with miRNA-137 mimic and scramble mimic. Logarithmic phase cells were treated with $0.25 \%$ trypsin. Six-well plates were coated with $0.5 \%$ agarose containing 2X DMEM, 10\% FBS and antibiotics. A $0.35 \%$ agarose containing the same supplements was placed on top of the previously prepared layer, followed by a suspension solution of $4 \times 10^{3}$ cells/well was subsequently placed on top of that, then the plate was incubated for 21 days at $37^{\circ} \mathrm{C}$ in a humidified atmosphere with $5 \% \mathrm{CO}_{2}$. Cells were stained with crystal violet and the number of foci was counted by eye using a Tanon 5200 chemiluminescent imaging system (Tanon Science and Technology Co., Ltd., Shanghai, China).

MTT assay. NSCLC A549 and NCI-H838 cell proliferation following miR-137 mimic and scramble mimic transfection was assessed using an MTT assay. NSCLC cells at a density of $4 \times 10^{3}$ cells/well were seeded into 96 -well plates following counting. Then, $5 \mathrm{mg} / \mathrm{ml}$ MTT was added into each well every $24 \mathrm{~h}$ for 7 days and incubated at $37^{\circ} \mathrm{C}$ for $4 \mathrm{~h}$. Then, crystals were dissolved with dimethyl sulfoxide, and the absorbance of each well was measured with a microplate reader set at $560 \mathrm{~nm}$ and replaced back into incubator.

Cell cycle analysis. Flow cytometry was used to determine the cell cycle distribution and analyzed using ModFit LT $^{\mathrm{TM}}$ software (Verity Software House, Inc., Topsham, ME, USA) with propidium iodide (PI) staining. Following transfection with miR-137 mimic or scramble mimic, A549 and NCI-H838 cells were seeded at a density of $1 \times 10^{6}$ cells/well into 6 -well plates. Cells were subsequently fixed with $70 \%$ ice-cold ethanol for $12 \mathrm{~h}$ at $4^{\circ} \mathrm{C}$ and then harvested through centrifugation at $(149 \times \mathrm{g}), 4^{\circ} \mathrm{C}$ for $5 \mathrm{~min}$. Cells were then washed with PBS three times and stained with $50 \mu \mathrm{g} / \mathrm{ml}$ PI containing $50 \mu \mathrm{g} / \mathrm{ml}$ RNase A, prior to being incubated in the dark for $30 \mathrm{~min}$ at room temperature.

Luciferase reporter assays. To observe the binding of miR-137 to SRC3 mRNA, the wild-type 3'-UTR and mutant 3'-UTR segments of SRC3 mRNA were amplified using the KOD-Plus PCR kit according to the manufacturer's protocol (Toyobo Co., Ltd.) and inserted into the pGL3-basic luciferase vector (Promega Corporation, Madison, WI, USA). The mutated putative miR-137 binding site in the SRC3 3'-UTR was generated using a Site-Directed Gene Mutagenesis kit (Beyotime Institute of Biotechnology, Haimen, China) according to the manufacturer's protocol. NSCLC cells were seeded at a density of $\sim 1 \times 10^{5}$ cells/well into 24 -well plates and cultured for $24 \mathrm{~h}$ prior to transfection. Co-transfections with $500 \mathrm{ng}$ pGL3-Basic firefly luciferase reporter and $100 \mathrm{nM}$ miR-137 mimic or scramble mimic into cells using Lipofectamine 
2000 for $4 \mathrm{~h}$ at $37^{\circ} \mathrm{C}$ was performed. Luciferase activity was measured at $48 \mathrm{~h}$ following transfection using a Luciferase Reporter Gene Assay kit (Promega Corporation).

Western blot analysis. A total of $48 \mathrm{~h}$ following transfection with miR-137 mimic or scramble mimic, total protein was extracted from the cell lysates following lysis using a RIPA buffer $(150 \mathrm{mM} \mathrm{NaCl}, 1 \%$ Nonidet P-40, $0.5 \%$ sodium deoxycholate, $0.1 \%$ SDS, $50 \mathrm{mM}$ Tris, $\mathrm{pH} 8.0$ ) and quantification using a BCA Protein Assay kit (Bio-Rad Laboratories, Inc., Hercules, CA, USA) of human NSCLC A549 and NCI-H838 cells. Total protein was separated on a $12 \%$ SDS-PAGE gel (20 $\mu \mathrm{g} /$ lane) and transferred to nitrocellulose membranes. The membranes were blocked with $5 \%$ non-fat milk for $2 \mathrm{~h}$ at room temperature, then incubated at $4^{\circ} \mathrm{C}$ for $12 \mathrm{~h}$ with primary antibodies directed against SRC3 (cat. no. 2126; Cell Signaling Technology, Inc., Danvers, MA, USA) and $\beta$-actin (cat. no. A1978; Sigma; Thermo Fisher Scientific, Inc.) (both dilution 1:1,000). Following washing with TBS-Tween 20, membranes were incubated at $37^{\circ} \mathrm{C}$ for $1 \mathrm{~h}$ with horseradish peroxidase-conjugated secondary antibody (cat. no. 7074; dilution, 1:2,000; Cell Signaling Technology, Inc.) and then visualized using a Pierce ${ }^{\mathrm{TM}}$ ECL Western Blotting kit (Thermo Fisher Scientific, Inc.).

Statistical analysis. Each experiment was repeated $\geq 3$ times. Statistical analysis was performed using SPSS software (version 12.0; SPSS, Inc., Chicago, IL, USA). All results are presented as the mean \pm standard deviation and were compared using a two-tailed Student's $t$-test. Linear correlation analysis was used to analyze the correlation between the expression of protein and miRNA in the clinical samples. $\mathrm{P}<0.05$ was considered to indicate a statistically significant difference.

TargetScan Prediction. miRNA and UTR targeting predictions were queried using the target prediction database, TargetScan (http://www.targetscan.org).

\section{Results}

Negative correlation between miR-137 and SRC3 expression in NSCLC tissue samples. miR-137 expression was measured in 40 healthy lung fibroblast and NSCLC tissue samples using semi-quantitative PCR. The data demonstrated that compared with healthy lung tissue samples, the NSCLC tissue group had significantly reduced endogenous miR-137 expression $(\mathrm{P}<0.05$; Fig. 1A), suggesting a role for miR-137 in NSCLC. The expression of SRC3 mRNA was investigated and was significantly increased in NSCLC tissue compared with adjacent healthy tissue samples $(\mathrm{P}<0.05$; Fig. 1B). Furthermore, to evaluate miR-137 modulation of SRC3 at the gene expression level, the association between the expression of miR-137 and SRC3 was investigated in NSCLC tissue samples. It was demonstrated that miR-137 expression was negatively correlated with SRC3 expression in NSCLC $\left(\mathrm{R}^{2}=0.5416 ; \mathrm{P}<0.01\right.$; Fig. 1C), indicating that miR-137 regulates the expression of $\mathrm{SRC} 3$.

miR-137 inhibits NSCLC cell proliferation. In order to evaluate the association between miR-137 expression and NSCLC cell growth, miR-137 mimic or scramble mimic were transfected into A549 and NCI-H838 cells. Cell proliferation was measured using a soft agar colony formation assay (Fig. 2A-C) and an MTT assay (Fig. 2D and E). The results demonstrated that cells transfected with miR-137 mimic had a significant decrease in foci number $(\mathrm{P}<0.05$; Fig. $2 \mathrm{~B}$ and $\mathrm{C})$ and significantly reduced metabolic activity $(\mathrm{P}<0.05$; Fig. $2 \mathrm{D}$ and $\mathrm{E})$ by day 4 compared with cells transfected with the scramble mimic. These results indicate that miR-137 can induce cell colony formation and efficiently inhibit the proliferation of NCI-H838 and A549 NSCLC cells.

miR-137 induces cell cycle arrest and reduces the mRNA expression of cell cycle-associated proteins in NSCLC cells. The cell cycle distribution of A549 and NCI-H838 cells was analyzed using flow cytometry following transfection with miR-137 mimic or scramble mimic (Fig. 3). Following transfection with miR-137 there was a significant reduction in the percentage of cells in the S-phase of the cell cycle and a significant increase in the number of $\mathrm{G}_{1}$ cells in A549 (Fig. 3A) and NCI-H838 (Fig. 3B) cells compared with in the scramble mimic control groups (all $\mathrm{P}<0.05)$. However, no significant differences were observed in the percentage of cells in the $\mathrm{G}_{2} / \mathrm{M}$ phase of the cell cycle between the miR-137 mimic- and scramble mimic-transfected groups. To further ascertain the molecular mechanisms underlying miR-137-induced $\mathrm{G}_{1}$ cell cycle arrest, the expression level of PCNA, cyclin E, cyclin A1, cyclin A2 and p21 in the NSCLC cells lines was measured. This demonstrated that miR-137 mimic transfection significantly decreased the mRNA expression of PCNA, cyclin E, cyclin A1 and cyclin A2, and significantly increased the expression of p21, in A549 (Fig. 3C) and NCI-H838 (Fig. 3D) cells compared with the scramble mimic group (all $\mathrm{P}<0.05$ ). This data indicates that overexpression of miR-137 results in $G_{1}$ phase arrest and affects the expression of cell cycle-associated proteins.

miR-137 targets SRC3 mRNA in NCI-H838 and A549 cells. To investigate whether miR-137 directly targeted SRC3 mRNA in NCI-H838 and A549 cells, the specific locations of the binding sites were searched for using TargetScan, which predicted a putative binding site for miR-137 within the 3'UTR of SRC3 TR at nucleotides 869-876 (Fig. 4A). To further understand the association between miR-137 and the 3'UTR of SRC3, luciferase reporter genes were constructed with the 3'UTR of SRC3, with or without mutations at the predicted miR-137 binding regions, and the luciferase activity following miR-137 mimic transfection was measured. As illustrated in Fig. 4B, miR-137 mimic transfection resulted in a significant reduction in luciferase activity when co-transfected with the wild-type SRC3 3'-UTR compared with the scramble control in A549 cells $(\mathrm{P}<0.05)$. However, no significant difference in luciferase activity was observed in cells co-transfected with mutant SRC3 3'-UTR and miR-137 compared with the scramble control. Similar results were also observed in the NCI-H838 cell line (Fig. 4C). Finally, western blot analysis was performed to analyze SRC3 protein expression following transfection with miR-137 mimic or scramble mimic (Fig. 4D). The results revealed a notable decrease in SRC3 protein expression in NCI-H838 cells and A549 cells transfected with miR-137 mimic compared with scramble 

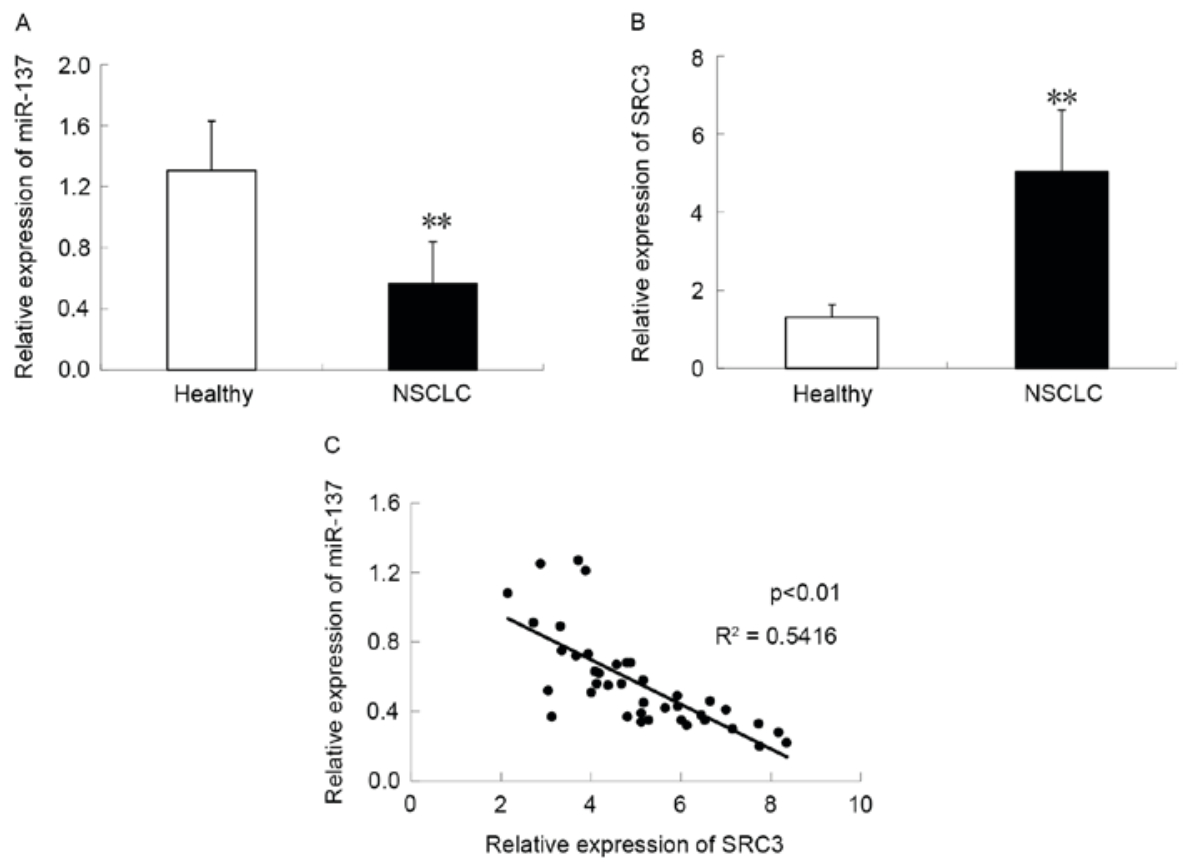

Figure 1. Negative correlation between miR-137 and SRC3 expression in NSCLC tissue samples. Semi-quantitative polymerase chain reaction was performed to measure the expression of (A) miR-137 and (B) SRC3 expression in NSCLC and adjacent healthy tissue samples. (C) SRC3 expression was negatively correlated with miR-137 expression in NSCLC tissue samples. ${ }^{* *} \mathrm{P}<0.05$. miR, microRNA; SRC3, steroid receptor coactivator-3; NSCLC, non-small cell lung cancer.

A

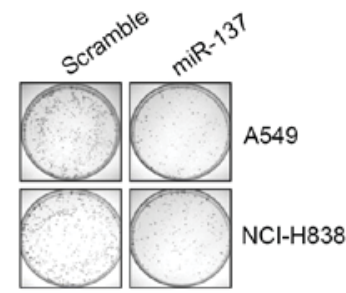

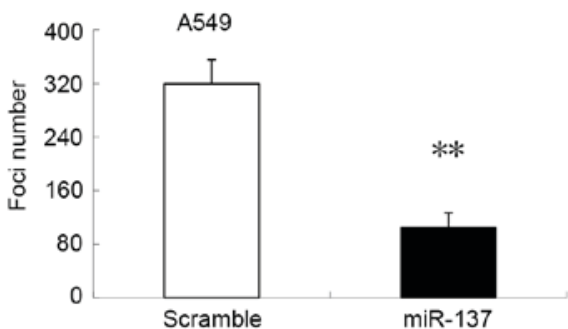

D

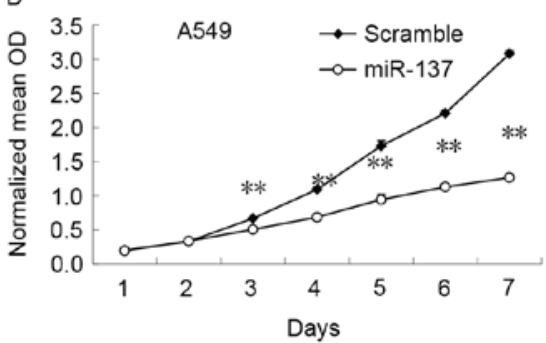

C

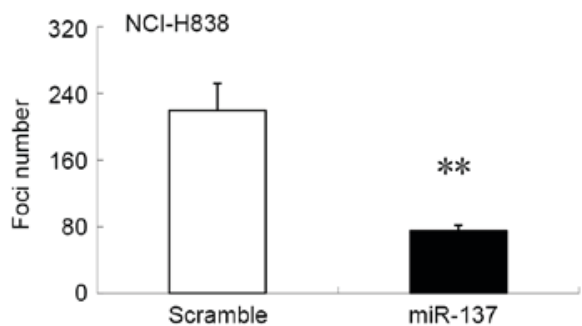

E

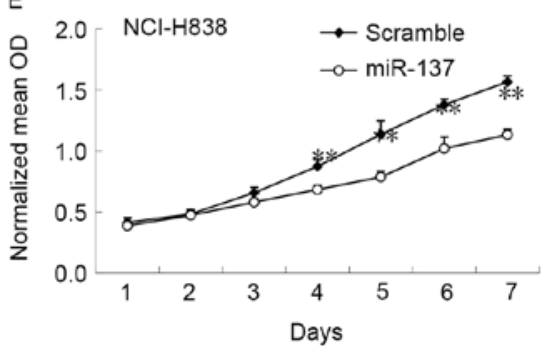

Figure 2. miR-137 inhibits NCI-H838 and A549 cell proliferation. (A) A soft agar colony formation assay was performed to measure the foci number of (B) A549 and (C) NCI-H838 cell lines following transfection with miR-137 mimic or scramble mimic. Cell proliferation activity was measured in (D) A549 and (E) NCI-H838 cells following transfection with miR-137 mimic or scramble mimic using an MTT assay. ${ }^{* *} \mathrm{P}<0.05$. miR, microRNA; OD, optical density.

mimic, which suggests that SRC3 may be a target of miR-137 in NSCLC. These results suggest that miR-137 binds to the
3'-UTR of SRC3 and thus reduces the protein expression of SRC3. 
A
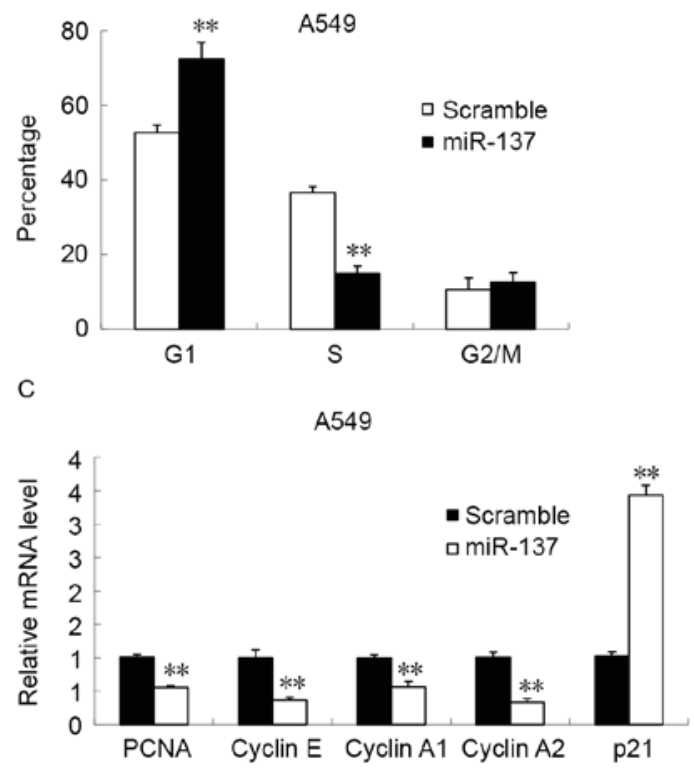

B
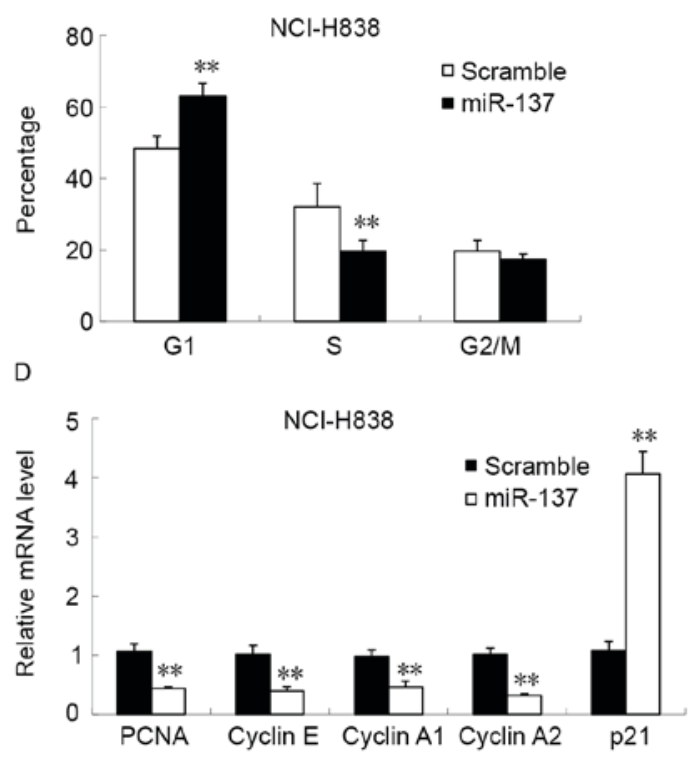

Figure 3. Effect of miR-137 on NCI-H838 and A549 cell cycle progression and the expression of cell cycle-associated proteins. miR-137 induced $\mathrm{G}_{1}$ stage cell cycle arrest in (A) A549 and (B) NCI-H838 cells. The effect of miR-137 on the expression of different cell cycle-associated proteins in (C) A549 and (D) NCI-H838 cells. ${ }^{* *} \mathrm{P}<0.05$. miR, microRNA; PCNA, proliferating cell nuclear antigen.
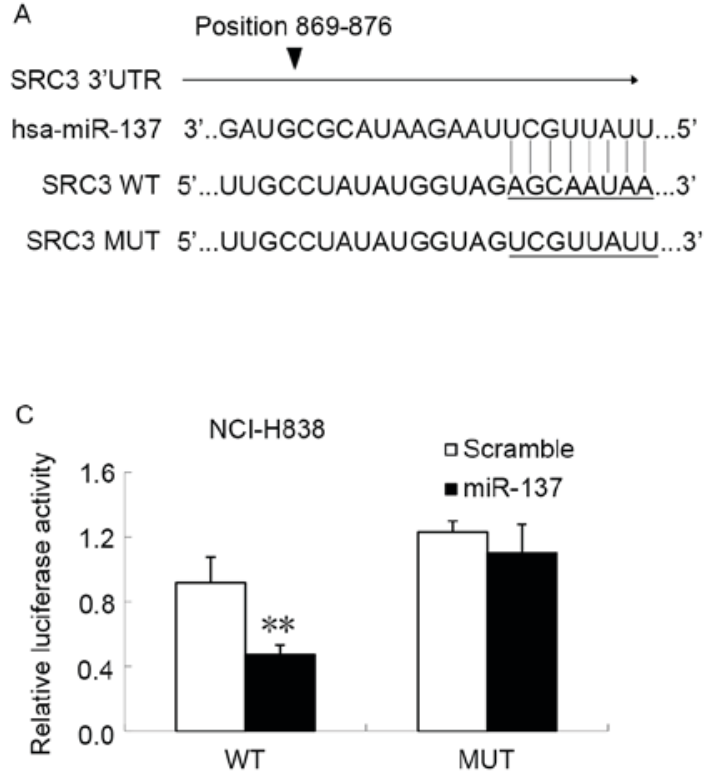

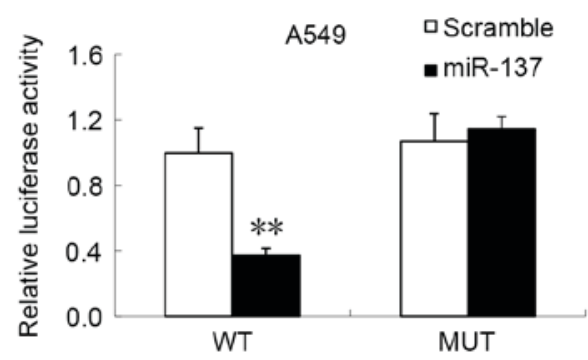

D

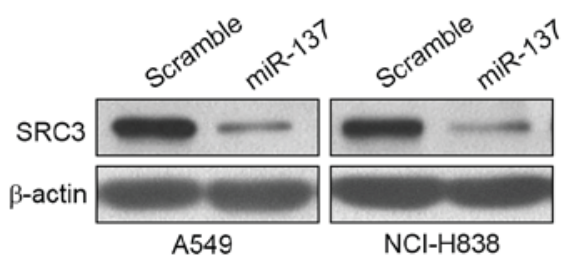

Figure 4. miR-137 inhibits SRC3 expression through an interaction with the SRC3 3'-UTR. (A) Schematic representation of SRC3 3'-UTR illustrating a putative miR-137 target site. Relative luciferase activity of the indicated SRC3 reporter construct in (B) A549 and (C) NCI-H838 cells co-transfected with the WT or MUT SCR3 3'UTR and miR-137 mimic or scramble mimic. (D) Western blot analysis of SRC3 protein expression in NCI-H838 and A549 cells transfected with miR-137 mimic or scramble mimic was performed using $\beta$-actin as the loading control. ${ }^{* *} \mathrm{P}<0.05$. miR, microRNA; SRC3, steroid receptor coactivator-3; UTR, untranslated region; WT, wild-type; MUT, mutated.

\section{Discussion}

An increasing number of studies have identified that miR-137 is frequently downregulated in numerous types of cancer cell, such as in brain stem tumor (27), colorectal cancer (28) and NSCLC (9) cells. However, several studies have reported that miR-137 is upregulated in lung cancer tissue (29), suggesting that miR-137 may serve different roles in different tumor microenvironments. Therefore, investigating the mechanisms underlying the involvement of miR-137 in different types of cancer may have important clinical implications.

In the present study, miR-137 was identified to be significantly downregulated in NSCLC samples compared with adjacent healthy tissue, which is consistent with previous studies performed by Zhu et al (10) and Bi et al (9). Previous studies have demonstrated that a low expression of miR-137 inhibits cell growth in vivo and in vitro through $\mathrm{G}_{1}$ phase cell cycle arrest, and impairs cell migration and invasion $(7,27)$. 
To investigate the effect of miR-137 on NSCLC cell growth, the colony forming and proliferation ability of cells was determined using soft agar colony formation assays and MTT assays, respectively. Transfection of miR-137 mimic resulted in a significant decrease in foci number and metabolic activity compared with the scramble mimic control groups. The results of the present study confirm that miR-137 induces $\mathrm{G}_{1} / \mathrm{S}$ cell cycle arrest; however, what causes cells to remain in the quiescent state remains unclear.

PCNA is a DNA polymerase sliding clamp that serves a role in DNA replication and repair (30). A previous study demonstrated that a high PCNA index resulted in an increase in cyclin E2 and proliferative activity in pancreatic cancer cells (31). Low levels of cyclins, particularly cyclin A and cyclin $\mathrm{E}$ have been suggested as a characteristic marker of cellular quiescence (32). For instance, the downregulation of cyclin E2, through regulation by miR-26a, was demonstrated to induce cell cycle arrest, inhibit cell proliferation and decrease tumor growth in pancreatic cancer (31). As a cell cycle arrest protein, $\mathrm{p} 21$ is able to protect cells from apoptosis and induces $\mathrm{G}_{1}$ phase cell cycle arrest by inactivating cyclin $\mathrm{A}$ / cyclin dependent kinase (CDK) 2 complexes (33). Furthermore, ectopic expression of miR-218 was demonstrated to induce $\mathrm{G}_{1} / \mathrm{S}$ checkpoint arrest, which resulted in the inhibition of glioma cell proliferation through the upregulation of p21 (34). Therefore, the expression of PCNA, cyclin E, cyclin A1, cyclin A2 and p21 were investigated in the present study. The results of the current study demonstrated that miR-137 mimic transfection significantly decreased the mRNA expression of PCNA, cyclin E, cyclin A1, cyclin A2, and significantly increased expression of $\mathrm{p} 21$ compared with the control. This further indicates that miR-137 induces NSCLC cell $\mathrm{G}_{1}$ phase arrest and suppresses cell proliferation by dysregulating the expression of different cell cycle proteins.

The inhibition of cell proliferation induced by low level miR-137 expression in NSCLC cell lines typically depends on the regulation of various target genes. For instance, miR-137 was revealed to suppress cell growth, migration and invasion in NSCLC cells through targeting paxillin (9), which encodes a focal adhesion-associated protein. Ectopic expression of miR-137 in lung cancer cells was demonstrated to significantly induce $\mathrm{G}_{1}$ phase cell cycle arrest, resulting in a significant decrease in cell growth in vivo and in vitro through downregulation of CDC42 and CDK6. A previous study revealed that miR-137 negatively regulates estrogen-related receptor $\alpha$ expression, an orphan nuclear receptor that was identified as a novel biomarker of breast cancer, and is involved in the repression of breast cancer cell proliferation and migration (8). Previous studies have identified SLC22A18 (15) and carboxyl-terminal binding protein 1 (35) as other target genes regulated by miR-137 in tumor cells.

Although SRC3 has been reported to be a target of miR-17-5p in breast cancer cells (19) and miR-195 in hepatocellular carcinoma cells (26), the association between miR-137 and SRC 3 has not yet been experimentally validated in NSCLC, to the best of our knowledge. Similar to previous identified target genes of miR-137 (8), in the present study SRC3 was demonstrated to be overexpressed in NSCLC samples, and a significantly negative correlation was identified between the expression of miR-137 and SRC3 in NSCLC tissue. In order to investigate the mechanisms of whether miR-137 inhibited cell proliferation through modulating SRC3 expression, a series of experiments were performed. TargetScan was used to predict a putative binding site for miR-137 within the SRC3 3'-UTR at nucleotides 869-876. In addition, wild-type SRC3 3'-UTR luciferase activity was significantly decreased following transfection with miR-137 mimic, but not in the mutant construct. Further experiments demonstrated that the expression of SRC3 was significantly reduced upon transfection with miR-137 mimic in A549 and NCI-H838 cells.

In conclusion, the results of the current study demonstrate that miR-137 inhibits cell proliferation in NSCLC by targeting the 3'UTR of SRC. Therefore, miR-137 may aid in providing novel diagnostic and therapeutic options for the treatment of patients with NSCLC in the future.

\section{References}

1. Jemal A, Center MM, DeSantis C and Ward EM: Global patterns of cancer incidence and mortality rates and trends. Cancer Epidemiol Biomarkers Prev 19: 1893-1907, 2010.

2. Siegel R, Naishadham D and Jemal A: Cancer statistics, 2012. CA Cancer J Clin 62: 10-29, 2012.

3. Yu JL, Simmons C, Victor JC, Han D, Hogeveen S, Leighl N and Verma S: Impact of new chemotherapeutic and targeted agents on survival in stage IV non-small cell lung cancer. Oncologist 16: 1307-1315, 2011.

4. He L and Hannon GJ: MicroRNAs: Small RNAs with a big role in gene regulation. Nat Rev Genet 5: 522-531, 2004.

5. Du L, Borkowski R, Zhao Z, Ma X, Yu X, Xie XJ and Pertsemlidis A: A high-throughput screen identifies miRNA inhibitors regulating lung cancer cell survival and response to paclitaxel. RNA Biol 10: 1700-1713, 2013.

6. Guo HL, Ingolia NT, Weissman JS and Bartel DP: Mammalian microRNAs predominantly act to decrease target mRNA levels. Nature 466: 835-840, 2010.

7. Chen QJ, Chen XB, Zhang MZ, Fan QX, Luo SX and Cao XG: miR-137 is frequently down-regulated in gastric cancer and is a negative regulator of Cdc42. Dig Dis Sci 56: 2009-2016, 2011.

8. Zhao YY, Li YP, Lou GY, Zhao L, Xu Z, Zhang Y and He F: MiR-137 targets estrogen-related receptor alpha and impairs the proliferative and migratory capacity of breast cancer cells. PLoS One 7: e39102, 2012.

9. Bi Y, Han Y, Bi H, Gao F and Wang X: miR-137 impairs the proliferative and migratory capacity of human non-small cell lung cancer cells by targeting paxillin. Hum Cell 27: 95-102, 2014.

10. Zhu X, Li Y, Shen H, Li H, Long L, Hui L and Xu W: miR-137 inhibits the proliferation of lung cancer cells by targeting $\mathrm{Cdc} 42$ and Cdk6. FEBS Lett 587: 73-81, 2013.

11. Dacic S, Kelly L, Shuai Y and Nikiforova MN: miRNA expression profiling of lung adenocarcinomas: Correlation with mutational status. Mod pathol 23: 1577-1582, 2010.

12. Ciafrè SA, Galardi S, Mangiola A, Ferracin M, Liu CG, Sabatino G, Negrini M, Maira G, Croce CM and Farace MG: Extensive modulation of a set of microRNAs in primary glioblastoma. Biochem Biophys Res Commun 334: 1351-1358, 2005.

13. Bandrés E, Cubedo E, Agirre X, Malumbres R, Zárate R, Ramirez N, Abajo A, Navarro A, Moreno I, Monzó M and García-Foncillas J: Identification by Real-time PCR of 13 mature microRNAs differentially expressed in colorectal cancer and non-tumoral tissues. Mol Cancer 5: 29, 2006.

14. Svoboda M, Izakovicova Holla L, Sefr R, Vrtkova I, Kocakova I, Tichy B and Dvorak J: Micro-RNAs miR125b and miR137 are frequently upregulated in response to capecitabine chemoradiotherapy of rectal cancer. Int J Oncol 33: 541-547, 2008.

15. Zhang B, Liu T, Wu T, Wang Z, Rao Z and Gao J: microRNA-137 functions as a tumor suppressor in human non-small cell lung cancer by targeting SLC22A18. Int J Biol Macromol 74: 111-118, 2015.

16. Li P, Ma L, Zhang Y, Ji F and Jin F: MicroRNA-137 down-regulates KIT and inhibits small cell lung cancer cell proliferation. Biomed Pharmacother 68: 7-12, 2014. 
17. Shi H, Ji Y, Zhang D, Liu Y and Fang P: MiR-135a inhibits migration and invasion and regulates EMT-related marker genes by targeting KLF8 in lung cancer cells. Biochem Biophys Res Commun 465: 125-130, 2015.

18. Zhen Q, Liu J, Gao L, Liu J, Wang R, Chu W, Zhang Y, Tan G Zhao X and Lv B: MicroRNA-200a targets EGFR and c-Met to inhibit migration, invasion and gefitinib resistance in non-small cell lung cancer. Cytogenet Genome Res 146: 1-8, 2015.

19. Hossain A, Kuo MT and Saunders GF: Mir-17-5p regulates breast cancer cell proliferation by inhibiting translation of AIB1 mRNA. Mol Cell Biol 26: 8191-8201, 2006.

20. Xu J and OMalley BW: Molecular mechanisms and cellular biology of the steroid receptor coactivator (SRC) family in steroid receptor function. Rev Endocr Metab Disord 3: 185-192, 2002.

21. Anzick SL, Kononen J, Walker RL, Azorsa DO, Tanner MM, Guan XY, Sauter G, Kallioniemi OP, Trent JM and Meltzer PS: AIB1, a steroid receptor coactivator amplified in breast and ovarian cancer. Science 277: 965-968, 1997.

22. Waters CE, Stevens A, White A and Ray DW: Analysis of co-factor function in a glucocorticoid-resistant small cell carcinoma cell line. J Endocrinol 183: 375-383, 2004.

23. Henke RT, Haddad BR, Kim SE, Rone JD, Mani A, Jessup JM, Wellstein A, Maitra A and Riegel AT: Overexpression of the nuclear receptor coactivator AIB1, (SRC-3) during progression of pancreatic adenocarcinoma. Clin Cancer Res 10: 6134-6142, 2004

24. Suen CS, Berrodin TJ, Mastroeni R, Cheskis BJ, Lyttle CR and Frail DE: A transcriptional coactivator, steroid receptor coactivator-3, selectively augments steroid receptor transcriptional activity. J Biol Chem 273: 27645-27653, 1998.

25. Wang $H$, Zhang D, Wu W, Zhang J, Guo D, Wang Q, Jing $T$, $\mathrm{Xu} \mathrm{C}$, Bian $\mathrm{X}$ and Yang K: Overexpression and gender-specific differences of SRC-3 (SRC-3/AIB1) immunoreactivity in human non-small cell lung cancer: an in vivo study. J Histochem Cytochem 58: 1121-1127, 2010

26. Jiang HL, Yu H, Ma X, Xu D, Lin GF, Ma DY and Jin JZ: MicroRNA-195 regulates steroid receptor coactivator-3 protein expression in hepatocellular carcinoma cells. Tumour Biol 35 6955-6960, 2014.
27. Silber J, Lim DA, Petritsch C, Persson AI, Maunakea AK, Yu M, Vandenberg SR, Ginzinger DG, James CD, Costello JF, et al: miR-124 and miR-137 inhibit proliferation of glioblastoma multiforme cells and induce differentiation of brain tumor stem cells. Bmc Med 6: 14, 2008.

28. Balaguer F, Link A, Lozano JJ, Cuatrecasas M, Nagasaka T, Boland CR and Goel A: Epigenetic Silencing of miR-137 is an early event in colorectal carcinogenesis. Cancer Res 70: 6609-6618, 2010

29. Huang T, Jiang M, Kong XY and Cai YD: Dysfunctions associated with methylation, microRNA expression and gene expression in lung cancer. PLoS One 7: e43441, 2012.

30. Shiomi N, Mori M, Tsuji H, Imai T, Inoue H, Tateishi S, Yamaizumi $\mathrm{M}$ and Shiomi T: Human RAD18 is involved in $\mathrm{S}$ phase-specific single-strand break repair without PCNA monoubiquitination. Nucleic Acids Res 35: e9, 2007.

31. Deng J, He M, Chen L, Chen C, Zheng J and Cai Z: The loss of miR-26a-mediated post-transcriptional regulation of cyclin E2 in pancreatic cancer cell proliferation and decreased patient survival. PLoS One 8: e76450, 2013

32. Cheung TH and Rando TA: Molecular regulation of stem cell quiescence. Nat Rev Mol Cell Bio 14: 329-340, 2013.

33. Levkau B, Koyama H, Raines EW, Clurman BE, Herren B, Orth K, Roberts JM and Ross R: Cleavage of p21 (Cip1/Waf1) and p27 (Kip1) mediates apoptosis in endothelial cells through activation of Cdk2: Role of a caspase cascade. Mol Cell 1: 553-563, 1998.

34. Jun GJ, Zhong GG and Ming ZS: miR-218 inhibits the proliferation of glioma U87 cells through the inactivation of the CDK6/ cyclin D1/p21(Cip1/Waf1) pathway. Oncol Lett 9: 2743-2749, 2015.

35. Deng Y, Deng H, Bi F, Liu J, Bemis LT, Norris D, Wang XJ and Zhang Q: MicroRNA-137 targets carboxyl-terminal binding protein 1 in melanoma cell lines. Int J Biol Sci 7: 133-137, 2011. 